\title{
Maternal Influenza Infection Causes Marked Behavioral and Pharmacological Changes in the Offspring
}

\author{
Limin Shi, ${ }^{1}$ S. Hossein Fatemi, ${ }^{2}$ Robert W. Sidwell, ${ }^{3}$ and Paul H. Patterson ${ }^{1}$ \\ ${ }^{1}$ Biology Division, California Institute of Technology, Pasadena, California 91125, ${ }^{2}$ Department of Psychiatry, University of Minnesota Medical School, \\ Minneapolis, Minnesota 55455, and ${ }^{3}$ Institute for Antiviral Research, Utah State University, Logan, Utah 84322
}

Maternal viral infection is known to increase the risk for schizophrenia and autism in the offspring. Using this observation in an animal model, we find that respiratory infection of pregnant mice (both BALB/c and C57BL/6 strains) with the human influenza virus yields offspring that display highly abnormal behavioral responses as adults. As in schizophrenia and autism, these offspring display deficits in prepulse inhibition (PPI) in the acoustic startle response. Compared with control mice, the infected mice also display striking responses to the acute administration of antipsychotic (clozapine and chlorpromazine) and psychomimetic (ketamine) drugs. Moreover, these mice are deficient in exploratory behavior in both open-field and novel-object tests, and they are deficient in social interaction. At least some of these behavioral changes likely are attributable to the maternal immune response itself. That is, maternal injection of the synthetic double-stranded RNA polyinosinic-polycytidylic acid causes a PPI deficit in the offspring in the absence of virus. Therefore, maternal viral infection has a profound effect on the behavior of adult offspring, probably via an effect of the maternal immune response on the fetus.

Key words: schizophrenia; autism; mental retardation; prepulse inhibition; acoustic startle; open field; novel object; clozapine; chlorpromazine; ketamine; poly(I:C)

\section{Introduction}

In an average year, influenza infections cause 10,000-20,000 deaths in the United States alone. In addition, over the last 300 years influenza pandemics have occurred every 10-20 years (Gust et al., 2001). Influenza infection of pregnant women can lead to complications in pregnancy such as stillbirth and miscarriage (Shahab and Glezen, 1994). It is important to note that even less severe maternal infections also can lead to devastating outcomes. Many epidemiological studies have found a significantly increased risk for schizophrenia in the offspring of women who were exposed to influenza during the second trimester of pregnancy. Similar associations have been made for rubella, measles, varicella-zoster, and diphtheria (Mednick et al., 1988; Brown et al., 2000). In addition, maternal viral infection has been cited as the "principal non-genetic cause of autism" (Ciaranello and Ciaranello, 1995). What these various insults are likely to have in common is a maternal antiviral response (Patterson, 2002).

To investigate how maternal viral infection may influence fetal brain development, it would be useful to have a mouse model to enable genetic manipulation. To help accomplish this, we report an initial study of the behavior of the offspring of mice that were given a respiratory infection with a mouse-adapted human influenza virus at mid-pregnancy. Using the same maternal in-

\footnotetext{
Received July 26, 2002; revised 0ct. 22, 2002; accepted 0ct. 24, 2002.

This work was supported by a gift from Ginger and Ted Jenkins and a Mettler Autism grant to P.H.P. S.H.F. is a Phyllis and Perry Schwartz National Alliance for Research on Schizophrenia and Depression Established Investigator. R.W.S. was supported by Contract N01-Al-65291 from the Virology Branch, National Institute of Allergy and Infectious Diseases, National Institutes of Health. We thank D. McDowell and F. Rooks for administrative help, J. Baer for assistance with mice, and L. Tecott for advice on behavioral tests.

Correspondence should be addressed to P. H. Patterson, Division of Biology 216-76, California Institute of Technology, Pasadena, CA 91125. E-mail: php@caltech.edu.

Copyright $\odot 2002$ Society for Neuroscience $\quad 0270-6474 / 02 / 220297-06 \$ 15.00 / 0$
}

fluenza virus infection paradigm, we previously found thinning of the neocortex and hippocampus, pyramidal cell atrophy, reduced levels of Reelin immunoreactivity, changes in the expression of neuronal nitric oxide synthase (nNOS) and synaptosomeassociated protein of $25 \mathrm{kDa}$ (SNAP-25), and macrocephaly in the brains of neonatal mice born to infected mothers (Cotter et al., 1995; Fatemi et al., 1998a,b, 2000, 2002).

\section{Materials and Methods}

Viral infection. On day 9.5 of pregnancy, BALB/c mice (Simonson Laboratories, Gilroy, CA) were anesthetized intraperitoneally with $10 \mathrm{mg} / \mathrm{kg}$ xylazine and $100 \mathrm{mg} / \mathrm{kg}$ ketamine and infused intranasally at the California Institute of Technology (Caltech) with $6 \times 10^{3} \mathrm{pfu}$ of the human influenza virus A/NWS/33CHINI in $90 \mu \mathrm{l}$ of PBS. Sham-infected mothers were treated identically but were infused with PBS. C57BL/6 mice (Simonson) were infected similarly at Utah State University (Fatemi et al., 1999, 2000), and the mothers and offspring were shipped to Caltech for behavioral analysis, which was performed $4-8$ weeks after arrival. Offspring were separated from their mothers after 3 weeks, and males and females were caged separately in groups of two to four.

Polyinosinic-polycytidylic acid injection. Polyinosinic-polycytidylic acid [poly(I:C); Sigma, St. Louis, MO] was diluted in PBS and injected intraperitoneally in pregnant $\mathrm{BALB} / \mathrm{c}$ females at day 9.5 of pregnancy at doses of 20, 10, 5, 2.5, and $0 \mathrm{mg} / \mathrm{kg}$.

Exploratory behavior and anxiety. The apparatus for the open-field and novel-object tests included a $50-\mathrm{cm}$-square open translucent plastic box with $17 \mathrm{~cm}$ sides. Twenty-five equal-size squares were marked on the bottom, and the box was illuminated by ambient fluorescent ceiling lights. In the open-field test, mice were placed individually near the center of the box, and their movements were followed by videotaping over a $10 \mathrm{~min}$ period. We quantified the time spent in the nine center squares, the number of times those squares were entered, and the number of times mice reared on their hindpaws. Using the same BALB/c mice $(9-10$ months old) that were used for the prepulse inhibition (PPI) assay de- 
scribed below, an observer blind to the history of the mice graded these behaviors.

The novel-object test was performed immediately after the open-field test without removing the mouse from the box. This was done to condition the mouse to the open-box paradigm before placing the object in the box. The object was a round silver cup $(4 \mathrm{~cm}$ in diameter at the closed end, $6 \mathrm{~cm}$ in diameter at the open end, and $4 \mathrm{~cm}$ high), and it was placed open end down, four squares from wherever the mouse was located, at the end of the open-field test, and we were careful to place it in a square immediately adjacent to a square lining the wall of the box. That is, the object was always in a center square but not far from the wall. The latency to contact the object and the numbers of contacts were quantitated in the initial 10 min period.

Spontaneous activity. Locomotor activity was monitored using a Photobeam Activity System (San Diego Instruments, San Diego, CA). A translucent cage was placed between photobeams. Individual mice were moved from their home cage to this cage, and ambulatory activity was defined as the successive interruption of two of the four beams crossing the cage for $40 \mathrm{hr}$.

Sensorimotor coordination. We analyzed mice in a rota-rod task using a Rota-rod Treadmill (Ugo Basile, Comerio, Italy) during the light phase of a $12 \mathrm{hr}$ light/dark cycle. When the mice were in position, the timer was set to zero, and the rota-rod was switched from $4 \mathrm{rpm}$ to accelerating mode (increasing $4 \mathrm{rpm}$ every $25 \mathrm{sec}$ ). After training the mice for $1 \mathrm{~d}$, we performed three trials each day for $3 \mathrm{~d}$, recording the longest duration that each mouse stayed on the rota-rod. These times were averaged for each session for each mouse, and means were calculated for the control $(n=10)$ and exposed $(n=10)$ groups.

Social behavior. One to $2 \mathrm{~d}$ after the open-field test, using the same open-field box, we examined social interaction between pairs of mice. We placed two mice (that had been housed separately) of the same sex and same experimental group in the center of the box $\sim 10 \mathrm{~cm}$ apart and monitored their contact with one another from videotapes of the $5 \mathrm{~min}$ test period under normal room lighting. A positive contact was scored when the nose of one mouse appeared to be $<2 \mathrm{~mm}$ away from the other mouse. The time spent in contact included any type of body contact.

Acoustic startle response. At 6-8 weeks of age, which represents late adolescence to early adulthood, the offspring were tested for their acoustic startle responses in a startle chamber (SR-LAB; San Diego Instruments) using standard methods described previously (Swerdlow and Geyer, 1998; Koch, 1999). A 5.1-cm-diameter Plexiglas cylinder mounted on a platform $(20.4 \times 12.7 \times 0.4 \mathrm{~cm})$ with a piezoelectric accelerometer unit attached below was located in a sound-attenuated chamber with a loudspeaker $(24 \mathrm{~cm}$ above the cylinder) and light. The delivery of acoustic stimuli was controlled by the SR-LAB computer. Sound levels were measured and calibrated with a Radio Shack (Fort Worth, TX) sound-level meter, and response sensitivities were calibrated using the SR-LAB Startle Calibration System. The 17 min test sessions consisted of six trial types: (1) pulse alone ( $120 \mathrm{~dB}), 40 \mathrm{msec}$ broadband burst; pulse preceded $100 \mathrm{msec}$ by a $20 \mathrm{msec}$ prepulse that was (2) $3 \mathrm{~dB}$, (3) $5 \mathrm{~dB}$, (4) $10 \mathrm{~dB}$, or (5) $15 \mathrm{~dB}$ over background; and (6) background ( $65 \mathrm{~dB})$ only (no stimulus). Test sessions followed an initial 5 min acclimation period. Our baseline data on the intensity and stability of the response and habituation to it are consistent with those determined previously (Swerdlow and Geyer, 1998).

For drug treatments, mice were placed in the startle box for PPI testing 5 min after intraperitoneal injection.

\section{Results \\ Viral infection}

Intranasal infusion of both $\mathrm{BALB} / \mathrm{c}$ and $\mathrm{C} 57 \mathrm{BL} / 6$ mice with $6 \times$ $10^{3} \mathrm{pfu}$ of human influenza virus caused sickness behavior (lethargy, sleepiness, ruffled fur, and lack of grooming) for several days, but loss of pregnancy was not common as long as the mice were not disturbed. A mild $(<50 \%)$ lung consolidation occurred in the mothers, with a virus titer in the lungs of $\sim 3-4 \times 10^{3} \mathrm{pfu}$

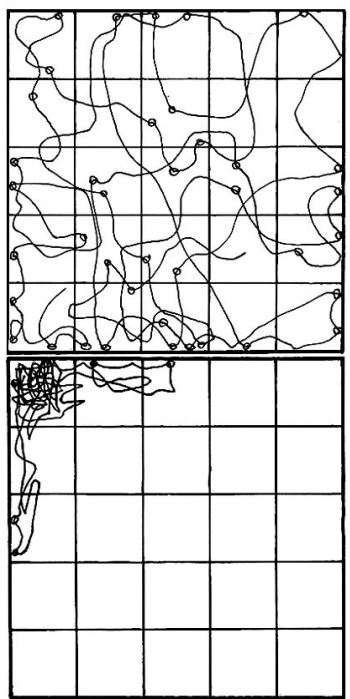

Figure 1. The exploratory behavior of mice born to infected mothers is very different from that of mice born to sham-infected mothers. The movements of a typical mouse from each group were traced from a videotape of a 10 min session in an open field subdivided into 25 squares by lines on the bottom of the box. Sites of rearing on hindpaws are illustrated by circles. Although these are not the most extreme examples of the behavior of mice from each group, it is clear that the mouse born to a sham-infected mother (top) responds very differently to the stress of this situation than the mouse born to a virus-infected mother (bottom).

early in the infection, and the titer dropped thereafter to undetectable levels. Fever does not occur in mice infected with influenza virus (Sidwell et al., 1986). For the BALB/c offspring, the birth weights of the control and experimental mice did not differ significantly $(1.50 \pm 0.03$ vs $1.34 \pm 0.09$ gm, respectively; $p=$ $0.12 ; n=9)$. However, the litter size was different $(8.25 \pm 1.03$ vs $4.14 \pm 0.26$ for sham-infected vs virus-infected mothers, respectively; $p=0.001 ; n=7)$.

\section{Exploratory behavior}

We used two assays of exploratory behavior with BALB/c mice, the open-field and novel-object tests (File, 1985; Weiss et al., 2000). Both of these tests are thought to be relevant for anxiety states in mental illness. In the open-field assay, the offspring of sham-infected versus virus-infected mothers are readily distinguished by the time that they spend in the center squares of the box and by the number of times that they enter those squares. Examples of the behavior of typical mice from the two groups are illustrated in Figure 1. Quantitation of the data reveals very significant differences in both measures of exploratory behavior (Table 1). The mice born to infected mothers spend nearly eightfold less time in the center squares $(p<0.0005$; two-tailed $t$ test), and most of their time is spent in the corners of the box (Fig. 1). These mice also enter the center squares nearly sixfold less often $(p<0.0016)$, and they explore their environment by rearing on their hindlegs fourfold less often $(p<0.001)$ (Table 1$)$. These findings were replicated in several smaller studies.

Although the mice born to infected mothers spent most of the 10 min test period in a corner of the box, they did not exhibit freezing behavior; they were moving frequently. To quantitate spontaneous activity in a home-cage environment, we used a photobeam-crossing apparatus. When the mice born to infected mothers initially were placed in this new home cage, they clearly displayed far less exploratory movement than the control mice (Fig. 2). Although the control mice actively explored this novel environment during both the first day and the first night, the 
Table 1. Maternal viral infection decreases exploratory behavior in adult offspring

\begin{tabular}{lccc}
\hline Open field test & Time in center & Number of times & \multicolumn{2}{l}{$\begin{array}{l}\text { Number of times } \\
\text { region of field }\end{array}$} & entering center & rearing \\
\hline Mice born to sham infected mothers & $108.5 \pm 30.0$ & $18.0 \pm 5.1$ & $31.8 \pm 7.5$ \\
Mice born to infected mothers & $14.5 \pm 6.6$ & $3.4 \pm 1.5$ & $7.7 \pm 1.6$ \\
& $p<0.0005$ & $p<0.0016$ & $p<0.001$ \\
& Time to first contact & Number of contacts \\
Novel object test & with object & with object \\
\hline Mice born to sham infected mothers & $169 \pm 65$ & $18.8 \pm 4.1$ \\
Mice born to infected mothers & $332 \pm 47$ & $6.3 \pm 1.8$ \\
& $p<0.05$ & $p<0.003$ \\
\hline
\end{tabular}

Fifteen control ( 7 males) and 23 experimental (12 males) BAL $B / c$ mice were tested sequentially in the open field and novel object tests, each for $10 \mathrm{~min}$. Their time, in seconds, for each measure of behavior was quantified from videotapes viewed by an observer blind to the history of the mice. Data are given as mean \pm SEM. A two-tailed ttest was used to assess the significance of the differences between the two groups in each test.

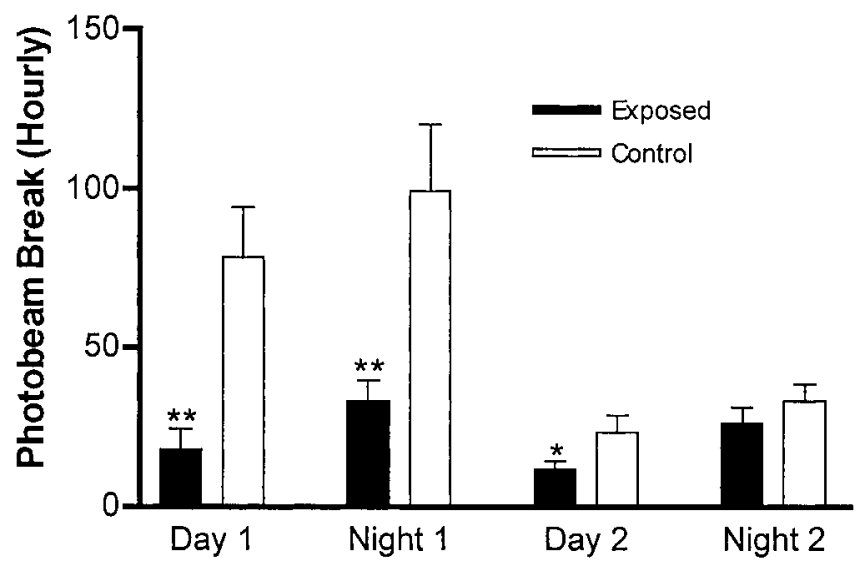

Figure 2. Spontaneous activity assayed by photobeam crossing. Individual mice were removed from their home cage and placed in the photobeam apparatus for $40 \mathrm{hr}$. The number of successive beam crossings (ambulation) was recorded and is expressed per hour. Control mice ( $n=8 ; 4$ males) explored this new environment extensively for the first $24 \mathrm{hr}$ period and then settled into a regular activity pattern on the second day. The mice born to infected mothers $(n=$ 10; 5 males) failed to display the early, active exploration pattern seen in the controls, but beginning on the second night, their baseline activity level was not different from the controls. ${ }^{*} p<0.05 ;{ }^{* *} p<0.01$.

experimental mice failed to do so. By the second night, however, the amount of ambulatory movement was indistinguishable in the two sets of mice. Therefore, the activity of the mice born to infected mothers does not differ from the controls once they become familiar with their home-cage environment. This is consistent with the observation that the experimental mice are not immobile in the open-field test; rather, they move frequently but rarely explore the center of the field (Fig. 1).

The novel-object test was performed immediately after the open-field test without removing the mouse from the box. Two measures of object exploration were quantitated. The mice born to infected mothers have an almost twofold greater latency in first contacting the object $(p<0.05)$, and they initiate almost threefold fewer contacts with the object than mice born to shaminfected mothers $(p<0.003)$ (Table 1$)$. These results were replicated in several smaller experiments.

\section{Sensorimotor coordination}

To test the mice for general sensorimotor coordination, we used the rota-rod in the accelerating mode. After an initial training session, the mice were tested three times daily for $3 \mathrm{~d}$. We averaged the time that each mouse stayed on the bar in each of the different sessions (tests 1,2 , and 3 ) over the $3 \mathrm{~d}$; there were no

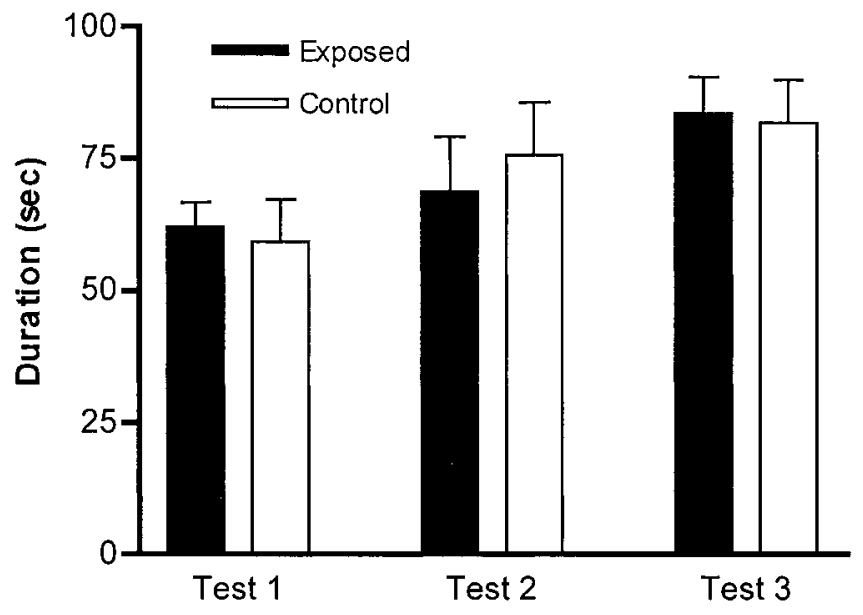

Figure 3. Exposed and control mice display no differences in the rota-rod test. Mice were tested three times daily for $3 \mathrm{~d}$ on a rota-rod in the accelerating mode. The results are expressed as the means of each of the daily test sessions, and we recorded the longest duration that each mouse stayed on the rota-rod. There was no significant difference between control $(n=10)$ and exposed $(n=10)$ groups for any of the three sessions.

Table 2. Maternal viral infection affects social behavior in adult offspring

\begin{tabular}{llc}
\hline & $\begin{array}{l}\text { Number of times } \\
\text { in contact }\end{array}$ & Time to first contact \\
\hline Mice born to sham infected mothers & $8.4 \pm 1.7$ & $24.6 \pm 6.8$ \\
Mice born to infected mothers & $3.1 \pm 0.9$ & $111.4 \pm 39.1$ \\
& $p<0.01$ & $p<0.07$ \\
\hline
\end{tabular}

The same mice used in the exploratory behavior tests were assayed (as pairs from the same groups) $1-2 \mathrm{~d}$ later in a social interaction test. The times, in seconds, of each behavior during the $5 \mathrm{~min}$ test period were graded from videotapes, and the significance of the differences assessed by a two-tailed $t$ test. Data are given as mean \pm SEM. Seven pairs of controls ( 4 female and 3 male pairs) and 10 pairs of mice born to infected mothers ( 5 female and 5 male pairs) were used.

significant differences between the mice born to virus-infected mothers and those born to sham-infected mothers (Fig. 3).

\section{Social behavior}

Using the same open-field box, we examined social interactions between mice that had not seen each other before but were of the same sex and experimental group. The mice born to infected mothers contacted each other 2.7-fold less frequently than the mice born to sham-infected mothers $(p<0.01)$ (Table 2$)$. There was also a four- to fivefold difference in latency to first contact, although this did not reach statistical significance. The large variance in the latter data set likely is attributable to our placing the mice near one another at the beginning of the test, which can lead to seemingly random contact in some cases.

\section{Acoustic startle response}

Acoustic startle response has been used effectively in both humans and rodents to measure sensorimotor gating. Acoustic stimuli are delivered, and startle responses are measured in an automated apparatus. When a prepulse-too small to cause a startle itself-precedes the startle stimulus, the response is diminished, a phenomenon that is termed PPI. In one experiment using the same BALB/c mice that were tested for exploratory and social behaviors, mice born to sham-infected mothers and mice born to virus-infected mothers were tested for PPI. The data for PPI of various prepulse intensities are shown in Figure 4. The offspring of infected mothers display significant PPI deficits at prepulses of $75 \mathrm{~dB}$ ( $10 \mathrm{~dB}$ higher than background) and $80 \mathrm{~dB}$ (15 $\mathrm{dB}$ higher than background). Similar results were obtained with 


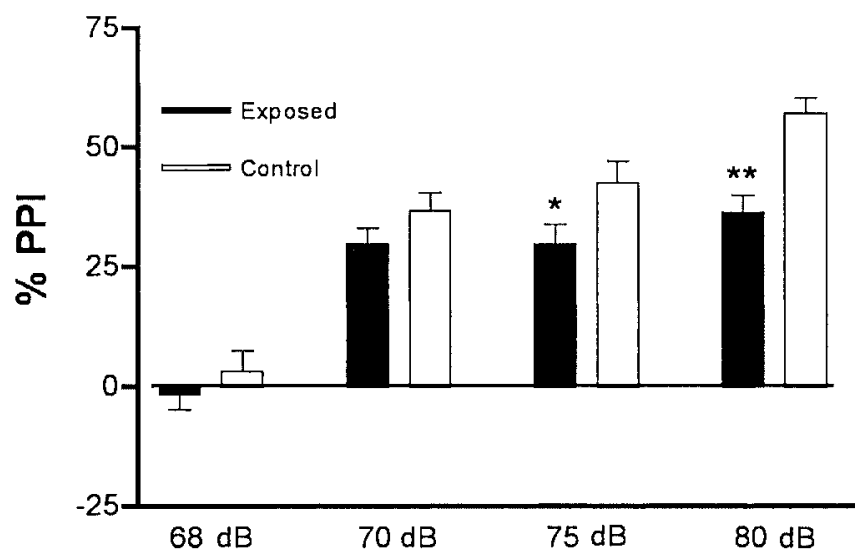

Figure 4. Responses of $B A L B / c$ mice in the prepulse inhibition (PPI) assay. Compared with mice born to sham-infected mothers (Control) ( $n=14 ; 8$ females), the mice born to infected mothers (Exposed) ( $n=29 ; 15$ females) display reduced PPI. These deficits are most significant at $75 \mathrm{~dB}$, which is $10 \mathrm{~dB}$ higher than background ( $p<0.05$ ), and at $80 \mathrm{~dB}$, which is $15 \mathrm{~dB}$ higher than background $(p<0.01)$.

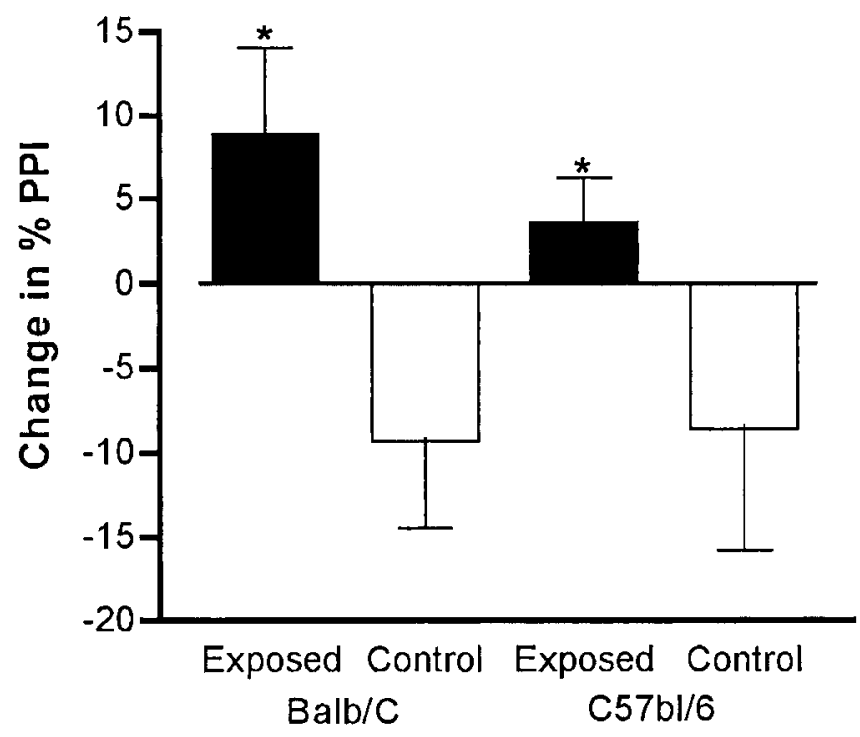

Figure 5. The effect of ketamine on PPI. The psychomimetic drug ketamine was administered 5 min before testing the acoustic startle response. As expected, ketamine diminished the PPI response (with an $80 \mathrm{~dB}$ prepulse) in the BALB/c mice born to sham-infected mothers (Control) ( $n=14 ; 8$ females), but it increased PPI in mice born to virus-infected mothers (Exposed) ( $n=29 ; 15$ females). The difference in the drug-induced increases between control groups and experimental groups is significant $(p<0.02)$. Similar results were observed for C57BL/6 mice ( $n=10$ and 48 for control groups and experimental groups, respectively; $p<0.04)$.

C57BL/6 mice; in one experiment, 10 mice born to sham-infected mothers and 48 mice born to virus-infected mothers were tested, and the latter group displayed a deficit at $80 \mathrm{~dB}$ (data not shown).

Pharmacological tests using psychoactive drugs that are known to modify PPI further emphasize the difference between the two groups of offspring. Ketamine was used as the psychomimetic agent because its antagonism with glutamate at the NMDA receptor exacerbates psychotic symptoms in schizophrenic patients and elicits hallucinations in normal subjects (Ellison, 1995; Malhotra et al., 1997). As expected from previous studies on rats (Swerdlow et al., 1998), injection of $6 \mathrm{mg} / \mathrm{kg}$ ketamine caused a decrease in PPI in control BALB/c mice (Fig. 5). In contrast, the mice born to virus-infected mothers displayed an actual increase

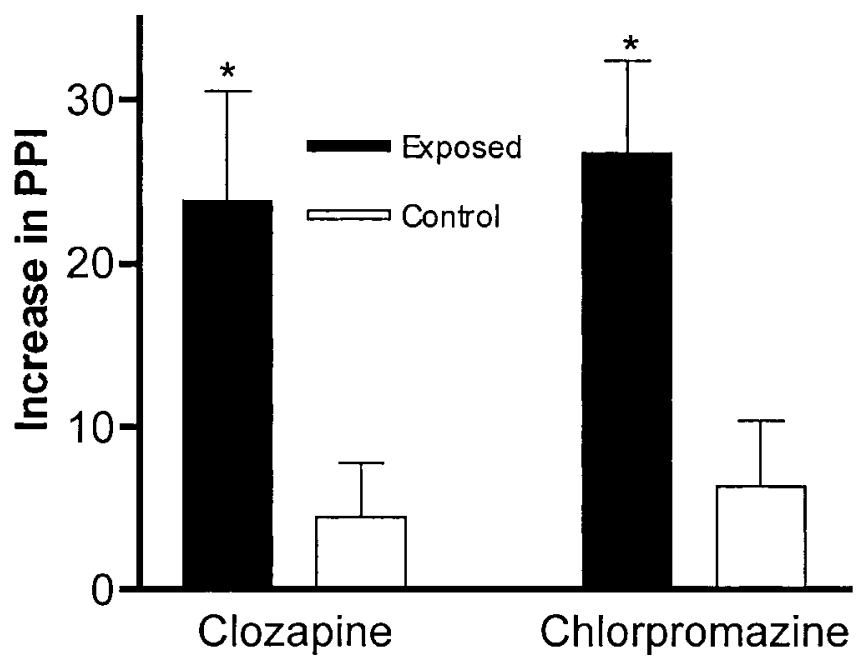

Figure 6. The effect of antipsychotic drugs on PPI. The typical antipsychotic drug chlorpromazine and the atypical antipsychotic drug clozapine were acutely administered to BALB/c mice, and PPI responses (with an $80 \mathrm{~dB}$ prepulse) were assayed. As expected from previous studies with rats, the sham-infected mice (Control) ( $n=10 ; 5$ females) displayed a modest increase in PPI when tested after drug injection. In contrast, the mice born to virus-infected mothers ( $E x$ posed) ( $n=21 ; 12$ females) displayed an extremely large increase in PPI after drug administration. The difference in the drug-induced increases between the control group and the experimental groups is significant $\left({ }^{*} p<0.03\right)$. Note that the data are expressed as the percentage of PPI increase.

in PPI in response to ketamine. Strikingly similar results were found for C57BL/6 mice (Fig. 5).

The difference between these groups of offspring is highlighted further by acute administration of dopamine-receptor blockers. Clozapine, a commonly used, atypical antipsychotic drug is known to increase PPI in rodents (Swerdlow et al., 1998), and it did so in our control BALB/c mice in a dose-dependent manner (data not shown). The mice born to infected mothers, however, displayed a fivefold greater increase in PPI in response to $2 \mathrm{mg} / \mathrm{kg}$ clozapine (Fig. 6). The same results were observed in the C57BL/6 mice (data not shown). In addition, very similar results were obtained with both strains of mice using $2 \mathrm{mg} / \mathrm{kg}$ chlorpromazine, a typical antipsychotic drug (Fig. 6). Therefore, the antipsychotic drugs corrected the PPI deficit in the experimental group, and these mice displayed a marked hypersensitivity to these drugs.

These pharmacological results also indicate that the mice born to infected mothers do not have an intrinsic auditory deficit, because they respond more strongly than control mice to the prepulse under these circumstances. The finding that the mice born to infected mothers display a very clear PPI response to the $70 \mathrm{~dB}$ prepulse, which is only $5 \mathrm{~dB}$ above the background noise level (Fig. 4), suggests that the mice had normal hearing.

Effect of the maternal immune response in the absence of virus

A fundamental question arising from these results is whether the alterations in behavior that we observed in the offspring of infected mothers are attributable to viral infection of the fetus or to a reaction to the maternal immune response. In addition, if the alterations are attributable to a maternal immune response reaction, could there be antiviral antibodies causing pathology by binding an epitope shared between the virus and the fetal brain? One approach to investigating this issue is to evoke an antivirallike immune response in the mother without using a virus. This 


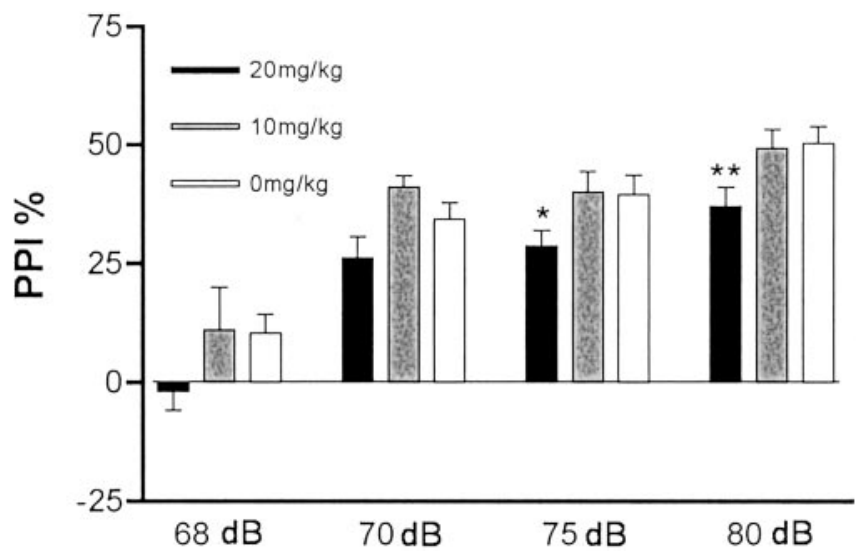

Figure 7. The effect of maternal immune response in the absence of virus. Pregnant $B A L B / C$ mice were injected intraperitoneally on day 9.5 of pregnancy with one of three doses of poly(l:C) to evoke an antiviral-like immune response. The offspring were tested for PPI at $4 \mathrm{~dB}$ prepulse levels at $6-8$ weeks of age. At the highest dose of poly $(\mathrm{l}: \mathrm{C})$, the offspring displayed a significant deficit in PPI $\left({ }^{*} p<0.05 ;{ }^{* *} p<0.01\right)$ ( $n=10$ for each group; 5 females each).

can be achieved by intraperitoneal injection of the synthetic double-stranded RNA poly(I:C). Poly(I:C) is known to evoke such an immune response in mice, including upregulation of major histocompatibility complex expression, as well as interferon and other cytokines [see references in Cella et al. (1999) and Verdijk et al. (1999)]. We tested several doses (20, 10, 5, 2.5, and $0 \mathrm{mg} / \mathrm{kg}$ ), and as shown in Figure 7, the offspring of the mothers injected with the highest dose of poly(I:C) display a deficit in PPI. This deficit is similar to that found in the offspring of virally infected mothers. Therefore, the maternal immune response, in the absence of virus, is sufficient to cause this behavioral change in the offspring. Similar results were obtained in a second, independent experiment.

\section{Discussion}

Our data on mice born to influenza virus-infected mothers show highly significant changes in behavior in the open-field, novelobject, and social interaction tests. These alterations in behavior likely reflect hyperanxiety in novel or stressful situations, which is a prominent feature of autism. Difficulty in handling stress also is observed in schizophrenia. In addition, these mice display a deficit in PPI and very distinctive PPI responses to acute administration of psychomimetic and antipsychotic drugs. Deficits in PPI are observed in several mental illnesses, including schizophrenia (Geyer et al., 1999) and autism (McAlonan et al., 2002). The strikingly abnormal responses to psychomimetic and antipsychotic drugs that we found in these mice suggest the possibility of alterations in dopaminergic and glutamatergic systems. A current theory of schizophrenia posits an imbalance in these two systems; such an imbalance in these mice could underlie their drug responses. Recent work also has identified changes in the glutamate neurotransmitter system in autism (Purcell et al., 2001). Therefore, the behavior of the mice born to infected mothers is consistent with that expected for a rodent version of schizophrenia and possibly autism. None of the tests used is specific for either of these disorders, however. There are several other viral infection models, primarily using postnatal rats, that also display significant behavioral abnormalities (for review, see Hornig and Lipkin, 2001; Pearce, 2001; Patterson, 2002).

The striking behavioral changes in mice born to infected mothers suggest that brain development was altered by this perturbation of the fetal environment. Using the same maternal in- fluenza virus infection paradigm, we previously found several alterations in brain histology (Cotter et al., 1995; Fatemi et al., 1999). It will be interesting to determine which of these (or other) molecular and morphological alterations correlates best with the PPI deficit found in the experimental mice. Such findings could shed light on the brain circuitry and the molecules involved in normal PPI and the acoustic startle response and, by analogy, on changes in autistic and schizophrenic subjects that exhibit PPI abnormalities.

The larger question is this: how does viral infection of the mother affect fetal brain development? We suspect that it is unlikely that the influenza virus actually infects the fetal brain because nonlethal strains of the virus are restricted most often to the respiratory tract, where cytokine responses are critical for the resolution of infection (Williams and MacKenzie, 1977; Irving et al., 2000; Tumpey et al., 2000; Van Reeth, 2000). Although the strain that we used can be neurotropic (Stuart-Harris et al., 1985), we were unable to detect virus in the brains of neonatal mice born to infected mothers using a plaque assay and cultured brain tissue (R. W. Sidwell, unpublished observations). Tests for antiviral antibody staining of the brains were negative, and there were no signs of encephalitis in sections from these neonatal brains (S. H. Fatemi, unpublished observations). In addition, preliminary RT-PCR assays failed to detect viral RNA in brains from fetuses taken from infected mothers (N. Tu, L. Shi, and P. H. Patterson, unpublished observations).

Perhaps more important, we found PPI deficits in the offspring of mothers injected with the synthetic double-stranded RNA poly(I:C), which evokes an antiviral-like immune response in mice. This indicates that the maternal immune response is sufficient to cause changes in the behavior of adult offspring, at least for PPI. Potential effectors of altered fetal brain development in this model then would include corticosteroids and cytokines. These possibilities are amenable to experimental manipulation. Such data then could be used to test therapeutic manipulations in ameliorating or preventing the deleterious effects of influenza virus infection on fetal brain development. In light of the evidence (cited in the introductory remarks) that maternal viral infection increases the risk of schizophrenia and autism, it is interesting that various immune abnormalities have been reported in schizophrenia (Wright and Murray, 1993; Muller et al., 1999; Nawa et al., 2000; Boin et al., 2001; Rothermundt et al., 2001) and autism (Burger and Warren, 1998; Jyonouchi et al., 2001).

We chose day 9.5 for infection in this study because it is approximately mid-pregnancy in the mouse, and human epidemiological studies highlight the second trimester as the critical time for influenza as a risk factor. This stage in the mouse coincides with neural crest migration to the face and midbrain and the time that Cajal-Retzius cells produce Reelin. Reelin is important in neuroblast migration, and its expression is abnormal in schizophrenic brains (Impagnatiello et al., 1998; Fatemi et al., 1999), which is consistent with the developmental theory of this disorder (Marenco and Weinberger, 2000; Nawa et al., 2000; Torrey and Yolken, 2000). Given that several parts of the mouse brain develop later than in the human, the study of mice born to mothers with late-pregnancy infections could reveal equally interesting results.

In addition to the relevance of this work to mental illness, investigation of potential therapeutic avenues is important because of the serious problems caused by maternal influenza infection in humans. Such infections can have serious consequences for the fetus, including miscarriage, premature birth, 
stillbirth, and early neonatal mortality, and there is also an increased risk of mortality for the mother (Shahab and Glezen, 1994).

\section{References}

Boin F, Zanardini R, Pioli R, Altamura CA, Maes M, Germarelli M (2001) Association between -G308A tumor necrosis factor alpha gene polymorphism and schizophrenia. Mol Psychiat 6:79-82.

Brown AS, Schaefer CA, Wyatt RJ, Goetz R, Begg MD, Gorman JM, Susser ES (2000) Maternal exposure to respiratory infections and adult schizophrenia spectrum disorders: a prospective birth cohort study. Schizophrenia Bull 26:287-295.

Burger RA, Warren RP (1998) Possible immunogenetic basis for autism. Ment Retard Dev Disabil Res Rev 4:137-141.

Cella M, Salio M, Sakakibara Y, Langen H, Julkunen I, Lanzavecchia A (1999) Maturation, activation, and protection of dendritic cells induced by double-stranded RNA. J Exp Med 189:821-829.

Ciaranello AL, Ciaranello RD (1995) The neurobiology of infantile autism. Annu Rev Neurosci 18:101-128.

Cotter D, Takei N, Farrell M, Sham P, Quinn P, Larkin C, Oxford J, Murray R, O'Callaghan E (1995) Does prenatal exposure to influenza in mice induce pyramidal cell disarray in the dorsal hippocampus? Schizophrenia Res 16:233-241.

Ellison G (1995) The N-methyl-D-aspartate antagonists phencyclidine, ketamine, dizocilpine as both behavioral and anatomical models of the dementias. Brain Res Rev 20:250-267.

Fatemi SH, Sidwell RW, Akhter P, Sedgewick J, Thuras P, Bailey K, Kist D (1998a) Human influenza viral infection in utero increases nNOS expression in hippocampi of neonatal mice. Synapse 29:84-88.

Fatemi SH, Sidwell RW, Kist D, Akhter P, Meltzer HY, Bailey K, Thuras P, Sedgewick J (1998b) Differential expression of synaptosome-associated protein $25 \mathrm{kDa}$ [SNAP-25] in hippocampi of neonatal mice following exposure to human influenza virus in utero. Brain Res 800:1-9.

Fatemi SH, Emamian ES, Kist D, Sidwell RW, Nakajima K, Akhter P, Shie A, Sheikh S, Bailey K (1999) Defective corticogenesis and reduction in Reelin immunoreactivity in cortex and hippocampus of prenatally infected neonatal mice. Mol Psychiat 4:145-154.

Fatemi SH, Cuadra AE, El-Fakahany EE, Sidwell RW, Thuras P (2000) Prenatal viral infection causes alterations in nNOS expression in developing mouse brains. NeuroReport 11:1493-1496.

Fatemi SH, Earle J, Kamodia R, Kist D, Emamian ES, Patterson PH, Shi L, Sidwell R (2002) Prenatal viral infection leads to pyramidal cell atrophy and macrocephaly in adulthood: implications for genesis of autism and schizophrenia. Cell Mol Neurobiol 22:25-33.

File SE (1985) Models of anxiety. Br J Clin Prac 38:15-20.

Geyer MA, Braff DL, Swerdlow NR (1999) Startle-response measures of information processes in animals: relevance to schizophrenia. In: Animal models of human emotion and cognition (Haug M, Whalen, RE, eds), pp 103-116. Washington, DC: American Psychiatric Association.

Gust ID, Hampson AW, Lavachy D (2001) Planning for the next pandemic of influenza. Rev Med Virol 11:59-70.

Hornig M, Lipkin WI (2001) Infectious and immune factors in the pathogenesis of neurodevelopmental disorders: epidemiology, hypotheses and animal models. Ment Retard Dev Disabil Res Rev 7:200-210.

Impagnatiello F, Guidotti AR, Pesold C, Dwivedi Y, Caruncho H, Pisu MG, Uzunov DP, Smallheiser NR, Davis JM, Pandey GN, Pappas GD, Tueting P, Sharma RP, Costa E (1998) A decrease of reelin expression as a putative vulnerability factor in schizophrenia. Proc Natl Acad Sci USA 95:15718-15723.

Irving WL, James DK, Stephenson T, Laing P, Jameson C, Oxford JS, Chakraverty $\mathrm{P}$, Brown DWG, Boon ACM, Zambon MC (2000) Influenza virus infection in the second and third trimesters of pregnancy: a clinical and seroepidemiological study. Br J Obstet Gynecol 107:1282-1289.

Jyonouchi H, Sun SN, Le H (2001) Proinflammatory and regulatory cytokine production associated with innate and adaptive immune responses in children with autism spectrum disorders and developmental regression. J Neuroimmunol 120:170-179.

Koch M (1999) The neurobiology of startle. Prog Neurobiol 59:107-128.

Malhotra AK, Pinals DA, Adler CM, Elman I, Clifton A, Pickar D, Breier A (1997) Ketamine-induced exacerbation of psychotic symptoms and cognitive impairment in neuroleptic-free schizophrenics. Neuropsychopharmacology 17:141-150.

Marenco S, Weinberger DR (2000) The neurodevelopmental hypothesis of schizophrenia: following a trail of evidence from cradle to grave. Dev Psychopathol 12:501-527.

McAlonan GM, Daly E, Kumari V, Critchley HD, van Amelsvoort T, Suckling J, Simmons A, Sigmundsson T, Greenwood K, Russell A, Schmitz N, Happe F, Howlin P, Murphy DG (2002) Brain anatomy and sensorimotor gating in Asperger's syndrome. Brian 125:1594-1606.

Mednick SA, Machon RA, Huttunen MO, Bonett D (1988) Adult schizophrenia following prenatal exposure to influenza epidemic. Arch Gen Psychiat 45:189-192.

Muller N, Riedel M, Ackenheil M, Schwarz MJ (1999) The role of immune function in schizophrenia: an overview. Eur Arch Psychiat Clin Neurosci 249 [Suppl 4]:62-68.

Nawa H, Takahashi M, Patterson P (2000) Cytokine and growth factor involvement in schizophrenia: support for the developmental model. Mol Psychiat 5:594-603.

Patterson PH (2002) Maternal infection: window on neuroimmune interactions in fetal brain development and mental illness. Curr Opin Neurobiol 12:115-118.

Pearce BD (2001) Schizophrenia and viral infection during neurodevelopment: a focus on mechanisms. Mol Psychiat 6:634-646.

Purcell AE, Jeon OH, Zimmerman AW, Pevsner J (2001) Postmortem brain abnormalities of the glutamate neurotransmitter system in autism. Neurology 57:1618-1628.

Rothermundt M, Arolt V, Bayer TA (2001) Review of immunological and immunopathological findings in schizophrenia. Brain Behav Immunol 15:319-339.

Shahab SZ, Glezen WP (1994) Influenza virus. In: Viral diseases in pregnancy (Gonik B, ed), pp 215-223. New York: Springer.

Sidwell RW, Huffman JH, Call EW, Alaghamandan H, Cook PD, Robins RK (1986) Effect of selenazofurin on influenza A and B virus infections of mice. Antiviral Res 6:343-353.

Stuart-Harris CH, Schild GC, Oxford JA (1985) Influenza: the viruses and the disease, 2nd Ed. Littleton, MA: Publishing Sciences Group.

Swerdlow NR, Geyer MA (1998) Using an animal model of deficient sensorimotor gating to study the pathophysiology and new treatments of schizophrenia. Schizophrenia Bull 24:285-301.

Swerdlow NR, Bakshi V, Waikar M, Taaid N, Geyer MA (1998) Seroquel, clozapine and chlorpromazine restore sensorimotor gating in ketaminetreated rats. Psychopharmacology 140:75-80.

Torrey EF, Yolken RH (2000) Familial and genetic mechanisms in schizophrenia. Brain Res Rev 31:113-117.

Tumpey TM, Lu X, Morken T, Zaki SR, Katz JM (2000) Depletion of lymphocytes and diminished cytokine production in mice infected with a highly virulent influenza A (H5N1) virus isolated from humans. J Virol 74:6105-6116.

Van Reeth KV (2000) Cytokines in the pathogenesis of influenza. Vet Microbiol 74:109-116.

Verdijk RM, Mutis T, Esendam B, Kamp J, Melief DJM, Brand A, Goulmy E (1999) Polyriboinosinic polyribocytidylic acid (Poly(I:C)) induces stable maturation of functionally active human dendritic cells. J Immunol 163:57-61.

Weiss SM, Lightower S, Stanhope KJ, Kennett GA, Dourish CT (2000) Measurement of anxiety in transgenic mice. Rev Neurosci 11:59-74.

Williams K, MacKenzie JS (1977) Influenza infections during pregnancy in the mouse. J Hygiene 79:249-257.

Wright P, Murray RM (1993) Schizophrenia: prenatal influenza and autoimmunity. Ann Med 25:497-502. 